\title{
UPAYA MENINGKATKAN AKTIVITAS BELAJAR MATEMATIKA SISWA DENGAN MENERAPKAN MODEL PEMBELAJARAN KOOPERATIF TIPE NUMBERED HEADS TOGETHER (NHT) MENGGUNAKAN SOAL CERITA
}

\author{
${ }^{1}$ Annisyah Rahmah, ${ }^{2}$ Effie Efrida Muchlis, ${ }^{3}$ Dewi Herawaty \\ 1,2,3 Program Studi Pendidikan Matematika JPMIPA FKIP Universitas Bengkulu \\ email : 19annisarahma13@gmail.com, ${ }^{2}$ effie_efrida@yahoo.com, ${ }^{3}$ dewiherawaty@gmail.com
}

\begin{abstract}
Abstrak
Tujuan penelitian ini adalah untuk meningkatkan aktivitas belajar matematika siswa dengan menerapkan model pembelajaran kooperatif tipe Numbered Heads Together (NHT) menggunakan soal cerita. Jenis penelitian ini adalah penelitian tindakan kelas (PTK) dan dilaksanakan dalam tiga siklus dengan subjek penelitian siswa kelas VIII A SMPN 15 Kota Bengkulu. Instrumen penelitian berupa lembar observasi aktivitas siswa. Hasil penelitian menunjukan penerapan model pembelajaran kooperatif tipe Numbered Heads Together (NHT) menggunakan soal cerita dapat meningkatkan aktivitas belajar matematika siswa. Aktivitas siswa ditingkatkan dengan cara: a) Menetapkan kelompok belajar heterogen berdasarkan tingkat kemampuan akademis, b) Memberikan tanggung jawab kepada setiap anggota kelompok, c) Melakukan kegiatan bertukar informasi. Peningkatan aktivitas terlihat dari hasil observasi aktivitas siswa siklus I, II, III, yaitu 16,25 (kriteria cukup); 22,125 (kriteria cukup); 26,5 (kriteria aktif).
\end{abstract}

kata kunci: pembelajaran kooperatif, Numbered Heads Together (NHT), soal cerita, aktivitas belajar.

\begin{abstract}
The study aims to improve the student mathematics learning activities by applying cooperative learning model type Numbered Heads Together (NHT) using story problem. Type of this research is classroom action research (CAR) and carried out in three cycles with the research subjects were students of class VIII A SMPN 15 Bengkulu City. The instruments used in this study is the student activities observation sheet. The results showed that the application of cooperative learning model Numbered Heads Together (NHT) using story problem can increas the students mathematics learning activities. Student activities can be improved by: a) Establishing the study group heterogeneously on the level of academic ability, b) Providing responsibility to each group member, c) Conducting information exchange activities. Increased of students activities can be seen from the observation of student activites cycle I, II, III, which is 16.25 (enough criteria); 22.125 (enough criteria); 26.5 (active criteria).
\end{abstract}

keywords : cooperative learning, Numbered Heads Together (NHT), story problem, learning activities, learning outcomes.

\section{PENDAHULUAN}

Matematika merupakan salah satu cabang ilmu yang sangat diperlukan dalam kemajuan IPTEK maupun kehidupan sehari-hari. Kemampuan dalam matematika merupakan hal yang penting bagi keberhasilan hidup bermasyarakat. Sehingga matematika perlu dibekalkan kepada setiap peserta didik sejak SD, bahkan sejak TK.
Berdasarkan hasil wawancara yang telah dilakukan peneliti dengan guru mata pelajaran matematika di SMPN 15 Kota Bengkulu, terdapat permasalahan dalam proses pembelajaran matematika di kelas. Dalam kegiatan pembelajaran diskusi kelompok masih banyak siswa yang kurang aktif. Hal ini dikarenakan kecenderungan siswa yang 
mengandalkan salah satu temannya untuk menyelesaikan dan mempresentasikan tugas yang diberikan guru. Akibatnya diskusi kelompok tidak berjalan dengan efektif dan tugas tidak terselesaikan dengan maksimal.

Upaya perbaikan dalam kegiatan pembelajaran dikelas dilakukan dengan menerapkan model pembelajaran kooperatif tipe Numbered Heads Together (NHT). Model pembelajaran kooperatif tipe Numbered Heads Together (NHT) merupakan model pembelajaran kooperatif yang memberikan tanggung jawab kepada setiap anggota kelompok terhadap tugas yang diberikan guru melalui teknik penomoran. Model pembelajaran ini diharapkan mampu membuat setiap siswa berpartisipasi aktif dalam diskusi kelompok.

Salah satu pokok bahasan matematika yang tepat diaplikasikan ke dalam bentuk soal cerita yaitu Bangun Ruang Sisi Datar. Hal ini untuk memperlihatkan penggunaannya dalam kehidupan nyata, sehingga siswa menyadari bahwa matematika khususnya pokok bahasan Bangun Ruang Sisi Datar sangat penting dalam kehidupan dan diharapkan dapat membuat siswa lebih antusias dalam penyelesaian soal.

Berdasarkan latar belakang masalah tersebut, rumusan masalah dalam penelitian ini adalah :

- Bagaimana meningkatkan aktivitas belajar matematika siswa pada materi Bangun Ruang Sisi Datar dengan menerapkan model pembelajaran kooperatif tipe Numbered Heads Together (NHT) menggunakan soal cerita di kelas VIII A SMP N 15 Kota Bengkulu?

Adapun tujuan tujuan dari penelitian ini adalah :

- Untuk meningkatkan aktivitas belajar matematika siswa pada materi Bangun Ruang Sisi Datar dengan menerapkan model pembelajaran kooperatif tipe Numbered Heads Together (NHT) menggunakan soal cerita di kelas VIII A SMP N 15 Kota Bengkulu.

\section{A. Model Pembelajaran Kooperatif Tipe NHT Menggunakan Soal Cerita}

Pembelajaran kooperatif adalah suatu model pembelajaran dimana sistem belajar dan bekerja siswa dalam kelompok-kelompok kecil secara kolaboratif sehingga dapat merangsang siswa lebih bergairah dalam belajar" (Slavin dalam Isjoni, 2012: 15). Pada pembelajaran kooperatif siswa diberikan kesempatan untuk berkomunikasi dan berinteraksi sosial dengan siswa lainnya untuk mencapai tujuan pembelajaran. Guru bertindak sebagai motivator dan fasilitator. Artinya dalam pembelajaran kooperatif kegiatan aktif dengan pengetahuan dibangun sendiri oleh siswa dan siswa bertanggung jawab atas hasil pembelajarannya.

Model pembelajaran kooperatif yang sesuai untuk mengatasi permasalahan kecenderungan siswa mengandalkan temannya dalam pembelajaran diskusi kelompok adalah Model pembelajaran kooperatif tipe Numbered Heads Together (NHT). Model pembelajaran kooperatif tipe Numbered Heads Together (NHT) adalah suatu model pembelajaran berkelompok yang setiap anggota kelompok bertanggung jawab atas tugas kelompoknya, guna mendapatkan hasil diskusi yang berdasarkan pemahaman dan kesepakatan semua anggota kelompok.

Pokok bahasan yang diajarkan dalam penelitian ini yaitu Bangun Ruang Sisi Datar, pada pembelajarannya pokok bahasan ini sering diaplikasikan kedalam bentuk soal cerita. Soal cerita berguna untuk memperlihatkan penerapkan pengetahuan yang telah dimiliki siswa sebelumnya ke dalam kehidupan nyata. Sehingga siswa akan menyadari bahwa matematika khususnya materi Bangun Ruang Sisi Datar sangat penting dalam kehidupan 
mereka. Dengan demikian, soal cerita dalam matematika merupakan serangkaian kalimat yang mengandung konsep-konsep matematika dan berupa permasalahan dalam kehidupan sehari-hari yang menuntut untuk diselesaikan.

Pembelajaran kooperatif tipe NHT menggunakan soal cerita akan memberikan peluang kepada siswa untuk saling menuangkan ide-ide serta bertukar pendapat dalam menyelesaikan soal cerita. perpaduan model pembelajaran kooperatif tipe NHT dengan menggunakan soal cerita menekankan pada aktivitas siswa untuk bekerjasama dengan kelompok dalam menyelesaikan soal cerita. Sehingga siswa bisa memastikan setiap anggota kelompoknya mengetahui jawaban atau hasil diskusi.

Adapun Langkah-langkah pembelajaran kooperatif tipe NHT menggunakan soal cerita menurut Hamdayama (2014: 178-181) adalah sebagai berikut :

1. Tahap 1 : Pendahuluan

Guru membuka

pembelajaran, menyampaikan tujuan pembelajaran, memberi motivasi siswa, dan mengingatkan siswa mengenai materi prasyarat.

2. Tahap 2 : Penyajian Informasi

Guru menyampaikan materi kepada siswa dengan demonstrasi.

3. Tahap 3 : Numbering (Penomoran)

Guru membagi siswa menjadi beberapa kelompok yang beranggotakan 3-5 orang dan memberi mereka nomor sesuai jumlah siswa dalam setiap kelompok, sehingga tiap siswa dalam suatu kelompok tersebut memiliki nomor berbeda.

4. Tahap 4 : Questioning (Pengajuan Pertanyaan)

Guru membagikan LKS kepada setiap kelompok untuk dikerjakan, dimana soal yang digunakan dalam LKS adalah soal cerita.
5. Tahap 5 : Heads Together (Berpikir Bersama)

Guru memberikan kesempatan setiap siswa untuk berdiskusi dengan kelompoknya masing-masing dalam menyelesaikan LKS dan meyakinkan bahwa tiap orang mengetahui jawaban tersebut.

6. Tahap 6 : Answering (Pemberian Jawaban) Guru menyebut satu nomor tertentu dan siswa dengan nomor yang disebut oleh guru mempresentasikan hasil diskusi kelompoknya didepan kelas.

7. Tahap 7 : Evaluasi dan Penghargaan

Guru menegaskan kebenaran dari hasil diskusi yang telah dilakukan siswa dan memberi penghargaan kepada kelompok yang menjawab dengan benar.

8. Tahap 8 : Penutup

Guru bersama siswa menarik kesimpulan mengenai materi yang telah dipelajari.

\section{B. Aktivitas Belajar Siswa}

Aktivitas belajar adalah aktivitas yang bersifat fisik maupun mental yang mana dalam kegiatan belajar kedua aktivitas itu harus selalu berkaitan (Sardiman, 2011: 100). Pembelajaran matematika merupakan pembelajaran yang menuntut siswa untuk melakukan berbagai aktivitas belajar, baik aktivitas yang bersifat fisik maupun mental. Adapun menurut Paul B. Diedrich dalam Sardiman (2011: 101) ada beberapa jenis aktivitas dalam belajar yaitu:

1. Visual activities, yang termasuk didalamnya misalnya: membaca, memerhatikan gambar demonstrasi, percobaan, pekerjaan orang lain.

2. Oral activities, seperti: menyatakan, merumuskan, bertanya, memberi saran, mengeluarkan pendapat, mengadakan wawancara, diskusi, interupsi.

3. Listening activities, sebagai contoh mendengarkan: uraian, percakapan, diskusi, musik, pidato. 
4. Writing activities, seperti misalnya menulis cerita, karangan, laporan, angket, menyalin.

5. Drawing activities, misalnya: menggambar, membuat grafik, peta, diagram.

6. Motor activities, yang termasuk di dalamnya antara lain: melakukan percobaan, membuat konstruksi, model mereparasi, bermain, berkebun, beternak.

7. Mental activities, sebagai contoh misalnya: menanggapi, mengingat, memecahkan soal, menganalisis, melihat hubungan, mengambil keputusan.

8. Emotional activities, seperti misalnya: menaruh minat, merasa bosan, gembira, bersemangat, bergairah, berani, tenang, gugup.

\section{METODE}

Jenis penelitian yang dilakukan pada penelitian ini adalah Penelitian Tindakan Kelas (PTK). Penelitian Tindakan Kelas dilakukan untuk mengatasi permasalahan yang terjadi di kelas. Penelitian tindakan kelas adalah penelitian yang dilakukan di dalam kelas melalui refleksi diri dengan tujuan untuk memperbaiki proses pembelajaran melalui berbagai tindakan yang terencana dalam situasi nyata serta menganalisis setiap pengaruh dari perlakuan tersebut Menurut Sanjaya (2013: 26).

Pada penelitian ini instrumen yang digunakan oleh peneliti adalah lembar aktivitas siswa dan tes hasil belajar. Lembar observasi aktivitas siswa dalam penelitian ini berupa pengamatan terhadap aktivitas siswa selama proses belajar mengajar berlangsung. Lembar observasi aktivitas siswa di isi oleh dua orang pengamat yaitu guru dan teman sejawat. Sedangkan tes hasil belajar yang digunakan pada penelitian ini adalah tes tertulis. Tes yang dilakukan berupa tes akhir di setiap siklus.
Pengisian lembar observasi aktivitas siswa oleh dua orang pengamat berpedoman pada penskoran seperti pada tabel berikut ini :

Tabel 1. Kriteria Penilaian untuk Lembar Observasi Aktivitas Siswa

\begin{tabular}{|c|c|c|c|}
\hline No. & $\begin{array}{c}\text { Kriteria } \\
\text { penilaian }\end{array}$ & Notasi & Skor \\
\hline 1. & Kurang & K & 1 \\
\hline 2. & Cukup & C & 2 \\
\hline 3. & Baik & B & 3 \\
\hline
\end{tabular}

(Modifikasi Sudjana, 2011: 77)

Untuk menghitung rata-rata hasil penilaian lembar observasi aktivitas siswa dari kedua orang pengamat yaitu dengan menggunakan rumus yang dimodifikasi dari sudjana (2005: 67) sebagai berikut :

Skor Rata - Rata Tiap Siklus $=\frac{\text { Jumlah Skor }}{\text { Jumlah Pengamat }}$

Adapun kisaran skor penilaian untuk lembar observasi aktivitas siswa adalah sebagai berikut :

Tabel 2. Kriteria Skor Pengamatan Lembar Observasi Aktivitas Siswa

\begin{tabular}{|c|c|}
\hline Kategori Penilaian & Kisaran Skor \\
\hline Kurang Aktif & $10 \leq \mathrm{x} \leq 16$ \\
\hline Cukup Aktif & $16<\mathrm{x} \leq 23$ \\
\hline Aktif & $23<\mathrm{x} \leq 30$ \\
\hline
\end{tabular}

(Modifikasi Sudijono, 2014: 52-53)

Siklus penelitian ini dihentikan ketika kriteria keberhasilan tindakan telah tercapai. Kriteria kebarhasilan tindakan dalam penelitian ini ditetapkan berdasarkan ketuntasan belajar yang telah ditetapkan oleh sekolah dan pertimbangan peneliti. Adapun indikator keberhasilan dalam penelitian ini adalah :

- Hasil observasi aktivitas siswa dalam pelaksanaan pembelajaran berada pada kriteria baik yaitu berada pada interval $23<x \leq 30$ maka siswa dikatakan aktif, dan meningkat dari siklus sebelumnya. 


\section{HASIL DAN PEMBAHASAN}

Penelitian yang berjudul "Penerapan Model Pembelajaran Kooperatif Tipe Numbered Heads Together (NHT) Menggunakan Soal Cerita untuk Meningkatkan Hasil Belajar Matematika Siswa Kelas VIII A SMP Negeri 15 Kota Bengkulu" ini dilaksanakan dalam 3 siklus. Setiap siklusnya terdiri dari empat tahapan, yaitu : 1) Perencanaan, 2) Pelaksanaan, 3) Pengamatan, dan 4) Refleksi.

Proses pembelajaran setiap siklusnya diamati oleh dua orang pengamat. Pengamatan aktivitas belajar siswa dilakukan pengamat dengan menggunakan lembar observasi aktivitas siswa yang disusun peneliti berdasarkan pembelajaran kooperatif tipe NHT menggunakan soal cerita. Lembar observasi aktivitas siswa terdiri dari 10 aspek yang ditentukan untuk diamati oleh pengamat berdasarkan langkah pembelajaran kooperatif tipe NHT menggunakan soal cerita.

Berdasarkan hasil perhitungan skor yang diberikan pengamat pada lembar observasi, aktivitas siswa meningkat di setiap siklusnya terlihat pada gambar berikut :

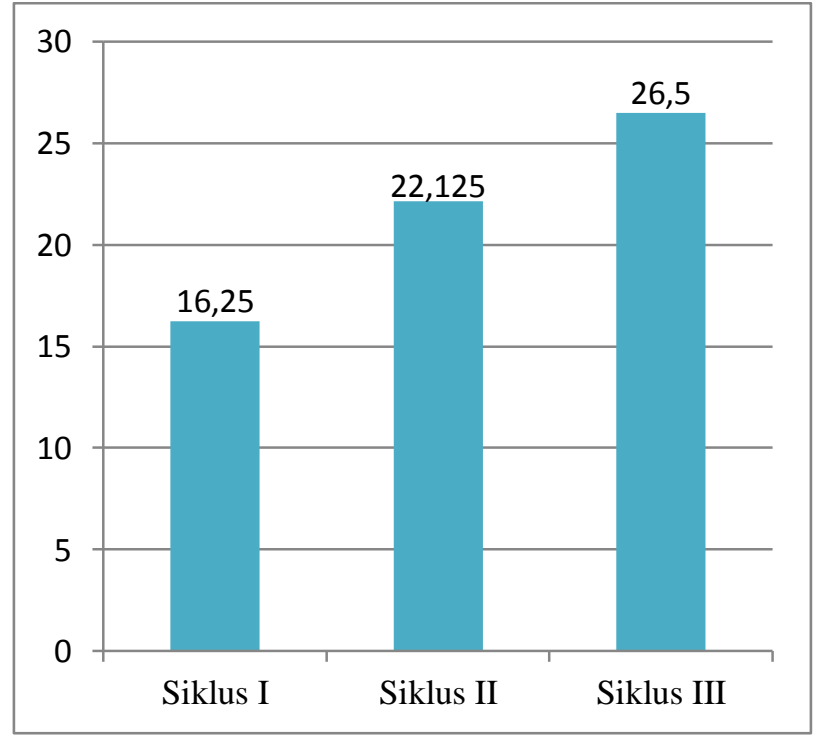

Gambar 1. Rekapitulasi Aktivitas Belajar Siswa

Pada siklus I kegiatan pembelajaran dengan model pembelajaran kooperatif tipe NHT menggunakan soal cerita belum berjalan dengan baik karena masih pada tahap penyesuaian. Pada siklus II aktivitas belajar siswa meningkat, akan tetapi pada tahapan Heads Together, masih ada kelompok yang anggotanya belum melaksanakan kegiatan bertukar informasi dengan baik sehingga ketika diminta untuk melakukan presentasi pada tahapan Answering siswa masih mengalami kesulitan. Pada siklus III aktivitas siswa kembali meningkat sehingga berada pada keriteria aktif, siswa dapat mengikuti kegiatan pembelajaran dengan menerapkan model pembelajaran kooperatif tipe Numbered Heads Together (NHT) menggunakan soal cerita dengan baik. Siswa sudah terlibat aktif dalam kegiatan pembelajaran diskusi kelompok dan presentasi hasil diskusi kelompok. Dengan demikian, dapat dikatakan bahwa penerapan model pembelajaran kooperatif tipe Numbered Heads Together (NHT) dapat meningkatkan aktivitas siswa.

\section{PENUTUP}

\section{Kesimpulan}

Penerapan model pembelajaran kooperatif tipe numbered heads together (NHT) menggunakan soal cerita dapat meningkatkan aktivitas belajar siswa dengan cara :

a. Menetapkan kelompok belajar secara heterogen berdasarkan tingkat kemampuan akademis agar siswa yang kemampuannya tinggi bisa membantu siswa yang berkemampuan rendah (Numbering).

b. Memberikan tanggung jawab kepada setiap anggota kelompok untuk membiasakan siswa bekerjasama dalam menyelesaikan tugas kelompok (Heads Together).

c. Pada tahapan Heads Together, siswa melakukan kegiatan bertukar informasi dengan anggota kelompok masing-masing agar setiap anggota kelompok memahami hasil kerja kelompoknya dan mampu mempresentasikan dengan baik(Answering). 
Peningkatan aktivitas belajar siswa terlihat dari peningkatan hasil observasi aktivitas belajar siswa disetiap siklusnya. siklus I aktivitas belajar siswa memperoleh skor rata-rata16,25 dengan kriteria cukup aktif. Pada siklus II aktivitas belajar siswa mengalami peningkatan skor rata-rata menjadi 22,125 , berada pada kriteria cukup aktif. Aktivitas belajar siswa kembali meningkat pada siklus III dengan skor rata-rata menjadi 26,5 dan berada pada kriteria aktif.

\section{Saran}

Berdasarkan penelitian yang telah dilakukan, maka peneliti memberikan beberapa saran, yaitu :

1. Disarankan kepada guru atau peneliti lain untuk melakukan penelitian lanjutan mengenai penerapan model pembelajaran kooperatif tipe Numbered Heads Together (NHT) menggunakan soal cerita dengan subjek penelitian dan pokok bahasan lainnya.

2. Pada kelas yang heterogen secara akademis, disarankan agar guru menerapkan pembelajaran kooperatif tipe Numbered Heads Together (NHT) menggunakan soal cerita guna meningkatkan aktivitas belajar siswa.

\section{DAFTAR PUSTAKA}

Hamdayama, Jumanta. 2014. Model dan Metode Pembelajaran Kreatif dan Berkarakter. Bogor: Ghalia Indonesia.

Isjoni. 2012. Cooperative Learning. Bandung: Alfabeta.

Sanjaya, H.Wina. 2013. Penelitian Tindakan Kelas. Jakarta: Kencana.

Sardiman, A.M. 2011. Interaksi dan Motivasi Belajar-Mengajar. Jakarta: PT Rajagrafindo Persada.

Sudijono, Anas. 2014. Pengantar Statistik Pendidikan. Jakarta: PT Rajagrafindo Persada.

Sudjana. 2005. Metoda Statistika. Bandung: PT Tarsito.

Sudjana, Nana. 2011. Penilaian Hasil Proses Belajar Mengajar. Bandung: PT Remaja Rosdakarya. 